\title{
Antioxidant and Anti-inflammatory Properties of Cultivated Mushrooms Grown in Mekelle City Tigray Ethiopia
}

\author{
Teklit Gebregiorgis Amabye \\ Department of Chemistry, College of Natural and Computational Science, Mekelle University, Mekelle, Tigray, Ethiopia
}

Email address:

teklitgeb@gmail.com

To cite this article:

Teklit Gebregiorgis Amabye. Antioxidant and Anti-inflammatory Properties of Cultivated Mushrooms Grown in Mekelle City Tigray Ethiopia. International Journal of Nutrition and Food Sciences. Vol. 4, No. 5, 2015, pp. 578-583.doi: 10.11648/j.ijnfs.20150405.20

\begin{abstract}
Traditionally mushrooms have been used for the prevention and treatment of a multitude disorders. Macro fungi regarding to the development of novel safe antimicrobials and antioxidants has become attractive source for researchers in the last decades. In the present study quantitative analysis of phytochemical constituents was carried out by using standard methods while 1,1 Diphenyl picryl hydroxyl(DPPH) Nitric oxide, Hydrogen peroxide free radical scavenging assay were used to evaluate the antioxidant properties of selected wild mushrooms. Anti- inflammatory capacity of samples was evaluated by HRBC membrane stabilization method. The results obtained from the study revealed that Agaricus Bosporus showed higher total phenol, mg flavonoid carotenoid, and lycopene and ascorbic acid contents of $(617.9 \pm 1) \mathrm{mg} / \mathrm{g},(62.52 \pm 1.13) \mathrm{mg} / \mathrm{g}$, (74.2 \pm 0.057$) \mu \mathrm{g} / \mathrm{mg},(49.6 \pm 0.17) \mu \mathrm{g} /$ and $28.8 \pm 0.34 \mathrm{mg} / \mathrm{g}$. All the species showed antioxidant potential but Russula delica proved to be more active while Agaricus Bosporus. Proved to be least one.
\end{abstract}

Keywords: Wild Mushrooms, Scavenging Effect, Total Phenol, Anti-oxidant, Anti-inflammatory

\section{Introduction}

Mushrooms have received increasing attention, since the primers of human civilization; wild mushrooms have been part of human diet for centuries, mainly because of variety of flavors and tastes they provide. They possess great potential for nutrition, as a rich sources of minerals and having high amounts of water, protein, fiber, and carbohydrates. Lipids are present in low values, which make valuable foods due to low-calorie and low-fat content (Kalac 2009, 2012). This enhances their marketability and economic contribution by approximately two billion dollars (Wang and Hall 2004, Pettenella, Kloehn and 52-68, 2007). Beyond the nutritional characteristics, a vast body of evidence indicates that mushrooms have been also extensively studied for their medicinal properties, mainly due to their richness in biologically active compounds that presented antioxidant, antimicrobial properties, strengthening the immune system and shielding against carcinogens (Ramesh and Pattar 2010). For the effective treatment of infections the growing emergence of drug-resistant bacterial strains is a serious threat to mankind. It is important to choose the most appropriate antibiotics and to use them appropriately to minimize the development of drug-resistant strains as it is impossible to prevent bacterial evolution. (Klein Smith and Laxminarayan, 2007). Another significant health issue is stress on the body due to aging, obesity, and detrimental lifestyle choices is, which often takes the form of oxidative damage to tissues. In Human body free radicals are constantly formed, during energy production in the mitochondrial respiratory chain, phagocytosis, fertilization, arachidonic acid metabolism and xenobiotic metabolism. Free radicals such as Super- oxide radicals $\left(\mathrm{O}_{2}\right)$, hydroxyl radicals $\left({ }_{-} \mathrm{OH}\right)$ and hydrogen peroxide $\left(\mathrm{H}_{2} \mathrm{O}_{2}\right)$ damage DNA, impair enzymes and structural proteins, and provoke uncontrolled chain reactions including lipid peroxidation which leads to the development of cancer, cardiovascular and neurological diseases, cataracts, diabetes, and rheumatoid arthritis. (Circu and Aw, 2010, Jeonget al., 2012). ROS (Reactive oxygen species) are also responsible in development of systemic inflammatory response syndrome, and then they activate nuclear factors thus inducing the synthesis of cytokines. Later, inflammatory mediators and adhesion molecules are also formed. Free radicals react with different cell components at site of inflammation thus leading to loss of function and cell death (Closa and Puy, 2004). However to protect against free radical damage almost all organisms have defense systems which is not sufficient. Many synthetic antioxidants, such as butylated 
hydroxyanisole and butylated hydroxytoluene, have side effects and are thought to be responsible for liver damage and carcinogenesis (Grice, 1988).

As a result to prevent oxidative damage and thus protect the human body, natural antioxidants are preferred in food applications. Natural substances, such as vitamins A, C and E, carotenoids, flavonoids and other simple phenolic compounds, are preferred. (Mackerras, 1995).Although there are many studies on nutrient compositions of different mushroom species. The current study sought to investigate the antioxidant and anti-inflammatory activities of wild mushrooms. The antioxidant activity of these mushroom extracts was also assessed by measuring their radical scavenging activity.

\section{Material and Methods}

\subsection{Material}

Four mushrooms were selected for the evaluation of antioxidant as well anti-inflammatory

I.e. Agaricus bisporous, PleurotusFlorida, Russula delica, Lyophyllum decastesywere obtained from mekelle research centerMekelle Ethiopia

\subsection{Determination of Bioactive Compounds}

\subsubsection{Standard and Reagents}

All the Standards solvents other chemicals were of analytic grade.

\subsubsection{Phenolic Compound Estimation}

$100 \mu \mathrm{l}$ of extract solution was mixed with $1.5 \mathrm{ml}$ of FolinCiocalteu reagent and incubated at room temperature for one minute followed by the addition of $1.5 \mathrm{ml}$ sodium carbonate $(60 \mathrm{~g} / \mathrm{l})$. The tubes were then vortex-mixed for $15 \mathrm{~s}$ and allowed to stand for 90 minutes in dark at room temperature. Absorbance was then measured at $725 \mathrm{~nm}$. Gallic acid was used as standard curve with concentration ranges from 1 to $100 \mu \mathrm{g} / \mathrm{ml}\left(\mathrm{R}^{2}=0.996\right)$ and the results were expressed as $\mathrm{mg}$ Gallic acid equivalent (GAE)/100g DW. All experiments were performed in triplicates. (Singleton et al., 1999)

\subsubsection{Flavonoid Contents}

$250 \mu \mathrm{l}$ extract of mushrooms was mixed with $1.25 \mathrm{ml}$ of distilled water and $75 \mu \mathrm{l}$ of a $5 \% \mathrm{NaNO}_{2}$ solution. $150 \mu \mathrm{l}$ of $10 \% \mathrm{AlCl}_{3} \cdot \mathrm{H}_{2} \mathrm{O}$ of was added after $5 \mathrm{~min}$. Then $275 \mu \mathrm{l}$ of distilled water and $500 \mu \mathrm{l}$ of $1 \mathrm{M} \mathrm{NaOHwereadded} \mathrm{to} \mathrm{the}$ mixture after $6 \mathrm{~min}$. The solution was then mixed well and the intensity of pink colour was measured at $510 \mathrm{~nm}$. The flavonoid compounds estimation was carried out in triplicate. Quercetin was used for calibration curve with concentration range of $20-100 \mu \mathrm{g} / \mathrm{ml}\left(\mathrm{R}^{2}=0.9938\right)$. The results were mean values \pm standard deviations and expressed as mil- ligrams of $(+)$ quercetin equivalents (CEs) per gram of extract. (Jiaet al., 1999)

\subsubsection{Ascorbic Acid Determination}

$100 \mathrm{mg}$ of dried extracts were extracted with $10 \mathrm{ml}$ of $1 \%$
Meta phosphoric acid for $45 \mathrm{~min}$ at room temperature and filtered through Whatman No.4 filter paper. The filtrate $(1 \mathrm{ml})$ were mixed with $9 \mathrm{ml}$ of 2, 6-dichloroindophenol and then absorbance was measured within $30 \mathrm{~min}$ at $515 \mathrm{~nm}$ against a blank. Content of ascorbic acid would be calculated on the basis of the calibration curve of authentic L-ascorbic with concentration range of $2-125 \mu \mathrm{g} / \mathrm{ml}\left(\mathrm{R}^{2}=0.9929\right)$. All the experiments were performed in triplicates. (Klein and Perry, 1982)

\subsection{5. $\beta$-Carotene and Lycopene Determination}

The dried extract $(100 \mathrm{mg})$ was vigorously shaked with 10 $\mathrm{ml}$ of acetone-hexane mixture (4:6) for $1 \mathrm{~min}$ and filtered through Whatman No.4 filter paper. The absorbance of the filtrate was measured at 453, 505, 645 and $663 \mathrm{~nm}$ (Nagata and Yamashita, 1992).

Content of $\beta$-carotene and lycopene were calculated by using following equations. Lycopene $(\mathrm{mg} / 100 \mathrm{mg})=-0.0458$ $\mathrm{A}_{663}+0.372 \mathrm{~A}_{505}-0.0806 \mathrm{~A}_{453}$

$\beta$-carotene $(\mathrm{mg} / 100 \mathrm{mg})=0.216 \mathrm{~A} 663-0.304 \mathrm{~A} 505+0.452 \mathrm{~A}$ 453

\subsection{Determination of Antioxidant Capacity}

\subsubsection{DPPH Free Radical Scavenging Activity}

Free radical scavenging activity of mushrooms extracts was determined by DPPH method.0.1mM of DPPH solution was prepared in methanol and $0.5 \mathrm{ml}$ of it was added to 0.5 $\mathrm{ml}$ of extract. The mixture was vortexed thoroughly and left for 45 minutes in dark at room temperature and absorbance was measured at $515 \mathrm{~nm}$ against blank. A lower absorbance represents a higher DPPH scavenging activity. The capability of scavenging DPPH radical was calculated using following equation

$$
\text { DPPH scavenging effect }(\%)=\left(1-\mathrm{A}_{\mathrm{S}} / \mathrm{A}_{\mathrm{C}}\right) \times 100
$$

Where $\mathrm{A}_{\mathrm{C}}$ is the absorbance of control containing DPPH solution and $A_{S}$ is absorbance of extract solution containing DPPH. (Hung and Morita, 2009).

\subsubsection{Nitric Oxide Scavenging Assay}

The interaction of extract of macro fungi with nitric oxide (NO) was assessed by nitrite detection method. The chemical source of nitric oxide was sodium nitroprusside $(10 \mathrm{mM})$ in 0.5 M phosphate buffer $\mathrm{pH} 7.4$ which spontaneously produced nitric oxide in aqueous solution. Nitric oxide interacted with oxygen to produce stable products, leading to the production of nitrites. After incubation for 5 hours at $3 \mathrm{C}$ $0.5 \mathrm{ml}$ of riess reagent ( $\alpha$-napthylethylenediamine $0.1 \%$ in water and sulphanilic acid $1 \%$ in $\mathrm{H}_{3} \mathrm{PO}_{4} 5 \%$ ) was added. Absorbance of solution was measured at $546 \mathrm{~nm}$. (Tewariet $a l ., 2014)$

\subsection{3. $\mathrm{H}_{2} \mathrm{O}_{2}$ Radical Scavenging Assay}

A solution of $\mathrm{H}_{2} \mathrm{O}_{2}(40 \mathrm{mM})$ was prepared in phosphate buffer $(7.4 \mathrm{pH})$. The concentration of $\mathrm{H}_{2} \mathrm{O}_{2}$ was determined by absorption at $230 \mathrm{~nm}$ using spectrophotometer. Extracts (10- $100 \mu \mathrm{g} / \mathrm{ml}$ ) were then added to $\mathrm{H}_{2} \mathrm{O}_{2}$ solution and after 
10 minutes of incubation the absorbance was determined at 230nm. Phosphate buffer without $\mathrm{H}_{2} \mathrm{O}_{2}$ was used as blank.Ascorbic acid was used as standard curve. (KhaledKhodjaaet al., 2014)

\subsubsection{HRBC Membrane Sterilization Assay}

Blood was collected from healthy volunteer who was not taken NSAID for two weeks. The collected blood was mixed with equal volume of sterilized $\mathrm{AL}$ sever solution $(2 \%$ dextrose, $0.8 \%$ sodium citrate, $0.5 \%$ citric acid, and $0.42 \%$ sodium chloride in water). The blood was centrifuged at $3000 \mathrm{rpm}$ for 15 minutes. Packed cell were washed with isosaline. Different concentration of extract (100, 250, 500 and $1000 \mu \mathrm{g} / \mathrm{ml}$ ) were prepared in isosaline. The assay mixture contained $0.5 \mathrm{ml}$ of extract $1 \mathrm{ml}$ phosphate buffer (0.15M, pH 7.4) $2 \mathrm{ml}$ of hypo saline $(0.36 \%)$ and $0.5 \mathrm{ml}$ $\mathrm{HRBC}$ suspension and incubated at $3 \mathrm{C}$ for 30 minutes and then centrifuged at $3000 \mathrm{rpm}$ for 20 minutes. Diclofenac sodium was used as reference standard. Instead of hypo saline $2 \mathrm{ml}$ of distilled water was used in control. The haemoglobin content in supernatant solution was estimated using spectrophotometer at $560 \mathrm{~nm}$. (Gandhidasan et, al 1991, Chippada et, al 2011).

$\%$ hemolysis was calculated by

$\%$ inhibition of hemolysis $=100(\mathrm{OD} 1-\mathrm{OD} 2) / \mathrm{OD} 1$

Where,
$\mathrm{OD}_{1}=$ Optical density of hypotonic buffer saline alone (control).

$\mathrm{OD}_{2}=$ Optical density of test sample in hypotonic buffer saline solution

\section{Results}

\subsection{Quantitative Phytochemical Analysis}

The determination of quantitative phytochemical content of methanolic extracts of selected mushrooms results as given in Table 1 that total contents of phenols ranged between $(240.9 \pm 0.5)-(617.9 \pm 1) \mathrm{mg} / \mathrm{g}$, total flavonoid contents $(39.55 \pm 0.65)-(62.52 \pm 1.13) \mathrm{mg} / \mathrm{g}$, total ascorbic acid contents $\quad(19.20 \pm 0.005)-(28.8 \pm 0.34) \mathrm{mg} / \mathrm{g}, \quad$ total $\beta$ carotenecontents $(49.46 \pm 0.75)-(74.2 \pm 0.057) \mu \mathrm{g} / \mathrm{mg}$ and total lycopene content (31.4 \pm 0.17$)-(49.6 \pm 0.17) \quad \mu \mathrm{g} / \mathrm{mg}$. The mushrooms Agaricusbisporous. Had the highest amount of phenol $(617.9 \pm 1 \mathrm{mg} \mathrm{GAE} / \mathrm{g})$ while Pleurotus Florida had least amount of phenol present $(240.9 \pm 0.5 \mathrm{mg}$ GAE/g). Flavonoids andascorbic acid were also obtained (Table 1) but in small amount in comparison to phenolic compounds while $\beta$ - carotene and lycopene were found in vestigial amount $(>91 \mu \mathrm{g} / \mathrm{g})$.

Table 1.Bioactive compounds present in different wild mushrooms and commercial cultivated mushrooms.

\begin{tabular}{lllllll}
\hline S.No. & Mushrooms & Phenols $(\mathbf{m g} / \mathbf{g})$ & Flavonoids(mg/g) & $\boldsymbol{\beta}$ - carotene $(\boldsymbol{\mu g} / \mathbf{m g})$ & Lycopene $(\boldsymbol{\mu g} / \mathbf{m g})$ & Ascorbic acid(mg/g) \\
\hline 1 & Agaricusbisporous & $617.9 \pm 1$ & $62.52 \pm 1.13$ & $74.2 \pm 0.057$ & $49.6 \pm 0.17$ & $28.8 \pm 0.34$ \\
2 & Pleurotus Florida & $240.9 \pm 0.5$ & $39.55 \pm 0.65$ & $49.46 \pm 0.75$ & $31.4 \pm 0.17$ & $19.20 \pm 0.005$ \\
3 & Russuladelica & $465.1 \pm 0.9$ & $55.36 \pm 0.64$ & $73.6 \pm 0.057$ & $48.9 \pm 0.34$ & $22.03 \pm 0.05$ \\
4 & Lyophyllumdecastes & $267 \pm 0.5$ & $44.82 \pm 0.65$ & $67.6 \pm 0.46$ & $46.1 \pm 0.28$ & $20.91 \pm 0.005$ \\
\hline
\end{tabular}

Results are presented as mean \pm SEM

\subsection{Anti -Oxidant Activity}

\subsubsection{DPPH Free Radical Scavenging Assay}

The antioxidant activities of extracts were expressed as
IC50 values of DPPH. The values varied from $342.72 \pm 1.21$ in Russuladelica. To $633.45 \pm 1.66 \mu \mathrm{g}$ extracted in Agaricusbisporous. As shown in Table 2.

Table 2. IC50 value of extracts of different samples of macro fungi for DPPH, Nitric oxide and H2O2 scavenging activity.

\begin{tabular}{lllll}
\hline S.no. & Macro fungi name & IC50 (DPPH) & IC50 (Nitric oxide) & IC50 (H2O2) \\
\hline 1 & Agaricusbisporous & $633.45 \pm 1.66$ & $439.8 \pm 1.8$ & $312.74 \pm 1.97$ \\
2 & Pleurotus Florida & $649.6 \pm 2.41$ & $436.9 \pm 2.4$ & $310.34 \pm 1.87$ \\
3 & Russuladelica & $342.72 \pm 1.21$ & $400.6 \pm 1.8$ & $304.39 \pm 1.97$ \\
4 & Lyophyllumdecastes & $373.8 \pm 0.75$ & $422.2 \pm 1.7$ & $307.32 \pm 1.91$ \\
\hline
\end{tabular}

\subsubsection{Nitric Oxide Scavenging Activity}

Our finding suggest that all the extracts substantially inhibited nitric oxide production with IC50 value ranges from $400.6 \pm 1.8 \quad$ (RussuladelicaRussuladelica.) to $439.8 \pm 1.8$ (Agaricusbisporous.) as shown in the above Table 2.

\subsubsection{Hydroxyl Radical Scavenging Assay}

Hydroxyl radical scavenging activity was quantified by measuring the inhibition of the degradation of 2deoxyribose by free radicals generated by Fenton reaction.
In the present study IC50 value of Hydroxyl radical scavenging activity was calculated and it was observed that the effect on hydrogen peroxide was higher having IC50value 312.74 \pm 1.87 in Agaricusbisporous and lower in Russuladelica having IC50 value $304.39 \pm 1.97$ as shown in the above Table 2 .

\subsubsection{HRBC Membrane Stabilization Assay}

The extracts of different mushrooms were studied for their in-vitro anti-inflammatory activity and highest activity was observed in Agaricusbisporous and least in Russuladelicaas shown in Below Table 3. 
Table 3. Anti-inflammatory activity of extracts as per HRBC Stabilizing Assay.

\begin{tabular}{llllll}
\hline S. No. & & \multicolumn{4}{l}{ Concentration used $(\boldsymbol{\mu g} / \mathbf{m l})$} \\
\hline & Standard & 2500 & 2000 & 1500 & 1000 \\
& Diclofenac sodium & $525 \pm 1.25$ & $470 \pm 2.82$ & $410 \pm 2.62$ & $383 \pm 1.82$ \\
& Isolates & $342 \pm 0.25$ & & & $1212 \pm 0.30$ \\
1 & Agaricusbisporous & $344 \pm 0.5$ & $198 \pm 0.75$ & $148 \pm 0.25$ & $98 \pm 0.30$ \\
2 & Pleurotus Florida & $335 \pm 0.15$ & $174 \pm 0.25$ & $99 \pm 0.15$ & $68 \pm 1.25$ \\
3 & Russuladelica & $338 \pm 0.20$ & $210 \pm 0.5$ & $164 \pm 0.25$ & $120 \pm 1.25$ \\
4 & Lyophyllumdecastes & & & & \\
\hline
\end{tabular}

Results are presented as mean \pm SEM

\section{Discussion}

In the present study total phenolic content were estimated by using FolinCiocalteu's reagent.

The reducing power was evaluated by measuring absorbance at $725 \mathrm{~nm}$. Flavonoid estimation was done by Ferric chloride method while estimation of Ascorbic acid was done by Meta phosphoric acid method and estimation of $\beta$ carotene lycopene was done by method given by Nagata and Yamashita in 1992.

It has been reported earlier that antioxidant activity is well correlated with content of their bioactive compounds especially phenols. Higher content of phenols accounts for better free radical scavenging effect due to their redox properties which can play an important role in absorbing in neutralizing free radicals quenching singlet and triplet oxygen or decomposing peroxides (Mishra et al., 2012). Ascorbic acid is naturally occurring compounds with antioxidant properties and is necessary for wound healing strengthens blood vessels walls. Flavonoids seem to be most promising poly phenolic compound and therefore known to have been a broad spectrum of chemical and biological activities including radical scavenging properties, antiallergenic, antiviral, anti-inflammatory, and vasodilation actions (Pereira etal., 2009 and Parajuli et al., 2012). Thus the extracts of the studied mushrooms may be goodalternatives for the treatment of diseases associated with excessive free radical generation and damage. Carotenoids like $\beta$ - carotene and lycopene exert antioxidant functions such as quenching of singlet oxygen and other electronically excited molecules and progression of many degenerative diseases (Sindhu et al., 2010).

It was revealed in the methanol extracts of mushrooms taken for quantitative analyses of phytochemicals constitute phenols, flavonoids ascorbic acid and $\beta$ - carotene and lycopene. These compounds possess various antioxidant functions therefore the mushrooms can be harnessed in the management of oxidative stress induced diseases.

Free radicals are known to play a definite role in a wide variety of pathological manifestations therefore, search for natural scavenger of reactive oxygen and nitrogen species seems to be highly desirable to protect against oxidative stress which is responsible for causing numerous diseases.

DPPH being stable free radical has advantage of being unaffected by certain side reactionsuch as metal ion chelation and enzyme inhibition. (Amar oweiz et al., 2004). Freshly prepared DPPH exhibit purple deep colour with absorption maximum at $517 \mathrm{~nm}$, the deep purple colour of DPPH disappears due to quenching of its free radicals by antioxidants present in the medium i.e. by providing hydrogen atom or by electron donation, via free radical attack on DPPH molecule and convert them to a colourless bleached product, 2,2 diphenyl-1 hydrazine. This reaction results in decrease in absorbance at $517 \mathrm{~nm}$, therefore more rapidly the absorbance decreases the more potent the antioxidant activity of extract. Results of this study suggest that the methanol extracts of mycelia cultures of mushrooms contains phytochemical constituents that are capable of donating hydrogen to a free radical to scavenge the potential damage.

Nitric oxide is free radical present in mammalian cells which are responsible for regulationof various physiological processes but the excess production of NO is associated with several diseases (Ray et al., 2002). Nitric oxide under aerobic condition reacts with oxygen to produce stable products nitrate and nitrite through intermediate $\mathrm{NO}_{2}, \mathrm{~N}_{2} \mathrm{O}_{4}$ and $\mathrm{N}_{4} \mathrm{O}_{3}$. Nitric oxide in higher concentration can be toxic therefore inhibition of nitric oxide is an important goal (Wang et al., 2005).

$\mathrm{H}_{2} \mathrm{O}_{2}$ has strong oxidizing properties. It occurs naturally at low concentration levels in air,water, human body, plants, microorganism and food (Gulcin, 2005).It can be formed invivo by oxidizing enzymes such as superoxide dismutase. It can cross membrane and slowly oxidize a number of compounds. $\mathrm{H}_{2} \mathrm{O}_{2}$ is rapidly composed into oxygen and water and this may produce hydroxyl radicals $(. \mathrm{OH})$ that can initiate lipid peroxidation and cause DNA damage (Sahreen et al., 2011). Methanol fractions of mushroom's mycelia cultures efficiently scavenged hydrogen peroxide which may be attributed to the presence of phenolic groups that could donate electrons to hydrogen peroxide, thereby neutralizing it into water.

In present study free radical scavenging activity assay of mushrooms were tested using methanol solution of stable free radical, and it was observed that Agaricusbisporous have more appreciable antioxidant activity while Russuladelica have least one. Thus other non-phenolic and flavonoids compound may be responsible for the antioxidant properties of Agaricusbisporous while other may have exhibited their antioxidant activity through different mechanism (Hamzahet. al 2014). 
Hypo tonicity induced HRBC membrane lysis i.e. HRBC membrane stabilization was taken as a measure of antiinflammatory activity. Currently much interest have been paid in the searching of medicinal plants with anti-inflammatory activity which may lead to the discovery of new therapeutic agent that is not only used to suppress the inflammation but also used in diverse disease conditions where the inflammation response is amplifying the disease process.

The vitality of the cells depends on the integrity of their membranes. Red blood cell exposure to hypotonic medium results in lysis of its membrane accompanied by hemolysis and oxidation of haemoglobin (Feirrali et al., 1992). The hemolytic effect of hypotonic solution is related to excessive accumulation of fluid within the cell which results in the rupturing of its membrane. It is therefore expected that compounds with membrane-stabilizing properties, should offer significant protection of cell membrane against injurious substances. The lysosome enzymes released during inflammation produces a variety of disorders. Their extracellular activity is said to be related to acute or chronic inflammation. There is increasing evidence that lysosome enzymes play an important role in the development of acute and chronic inflammation (Prakash et al., 2010). Most of the anti-inflammatory drugs exert their beneficial effects by inhibiting either release of these enzymes or by stabilizing lysosome membrane, which is one of the major event responsible for the inflammatory process.

The extracts exhibited membrane stabilization effect by inhibiting hypo tonicity induced lysis of erythrocyte membrane. The erythrocyte membrane is analogous to the lysosome membrane (Mounnissamy et al., 2008) and its stabilization implies that the extract may stabilize the lysosome membranes. Lysosome membrane stabilization is important in limiting the inflammatory response by preventing the release of lysosome constituents of activated neutrophil such as bactericidal enzymes and proteases, which cause further tissue inflammation and damage upon extra cellular release (Chaitanya et al., 2011). Some of the NSAIDs are known to possess membrane stabilization properties which may contribute to the potency of their anti-inflammatory effect. Though the exact mechanism of the membrane

Stabilization by the extract is not known yet, hypo tonicityinduced hemolysis may arise from shrinkage of the cells due to osmotic loss of intracellular electrolyte and fluid components.

From this result, it is suggested that anti-inflammatory activity observed in this study, may be due to the ability of the extracts to interfere with the early phase of inflammatory reactions, which may stimulate or enhance the efflux of these intracellular components there by exhibits the antiinflammatory activity.

\section{Conclusion}

The present study focuses on antioxidant and antiinflammatory effects of wild mushrooms collected from Mekelle Tigray Ethiopia. These mushrooms are not only consumed but also utilized for their medicinal properties hence there is a great need to exploit these wild occurring mushrooms from the dense and well expended forests ofin Tigrayto new drug discovery.

\section{Acknowledgements}

The authors are grateful to Department of chemistry University of Mekelle Tigray Ethiopia.

\section{Refrances}

[1] Agaricusbisporusharvested at different stages of maturity. Food Chem. 103, 1457-1464.

[2] Amarowiez R, Pegg R B, Rahimi Moghddam P, Barl B and Weil $\mathbf{J}$ A. Free radical scavenging capacity and antioxidant activity of selected plant species from the Canadian prairies. Food chemistry, 2004; 84: 551-562.

[3] Amarowiez R, Pegg R B, Rahimi Moghddam P, Barl B and Weil $\mathrm{J}$ A. Free radical scavenging capacity and antioxidant activity of selected plant species from the Canadian prairies. Foodchemistry, 2004; 84: 551-562.

[4] AOAC, 1995. Official methods of analysis (16th Ed.). Arlington VA, USA: Association of Official Analytical Chemists.

[5] Barros, L., Baptista, P., Ferreira, I. C. F. R. 2007. Effect of Lactariuspiperatus fruiting body maturity stage on antioxidant activity measured by several biochemical assays. Food. Toxicol. 45, 1731-1737.325-331.325-331.

[6] Barros, L., Correia, D. M., Ferreira, I. C. F. R., Baptista, P., Santos-Buelga, C. 2008a. Optimization of the determination of tocopherols in Agaricus sp. edible mushrooms by a normal phase liquid chromatographic method. Food Chem. 110, 10461050.

[7] Barros, L., Cruz, T., Baptista, P., Estevinho, L. M., Ferreira, I. C. F. R. 2008b. Wild and commercial mushrooms as source of nutrients and nutraceuticals. Food Chem. Toxicol. 46, 27422747.

[8] Beluhan, S., Ranogajec, A. 2011.Chemical composition and non-volatile components of Croatian wild edible mushrooms. Food Chem. 124, 1076-1082.

[9] Gandhidasan R, Thamaraichelyan A, Baburaj S. Antiinflammatory action of Lanneacoromandelicaby HRBC membrane stabilization. Fitoterapia, 1991; 62: 81-83.

[10] Gandhidasan R, Thamaraichelyan A, Baburaj S. Antiinflammatory action of Lanneacoromandelicaby HRBC membrane stabilization. Fitoterapia, 1991; 62: 81-83.

[11] Bonatti, M., Karnopp, P., Soares, H. M., Furlan, S. A., 2004. Evaluation of PleurotusostreatusandPleurotussajorcajunutritional characteristics when cultivated indifferent lignocellulosic wastes. Food Chem. 88, 425-428.

[12] Braaksma, A., Schaap, D. J. 1996. Protein analysis of the common mushroom Agaricusbisporus. Postharvest Biol. Tech. 7, 119-127.

[13] Çağlrirmak, N.2007. The nutrients of exotic mushrooms (Lentinula edodes andAida, F. M. N. A., Shuhaimi, M., Yazid, M., Maaruf, A. G. 2009. Mushroom as a potential source of prebiotics: a review. Trends Food Sci. Tech. 20, 567-575. 
[14] Chaitanya R, Sandhya S, David B, Vinod KR, Murali S. HRBC Membrane Stabilizing Property of Roor, Stem and Leaf of Glochidionvelutinum. Int J Res Pharmacist Biomed Sci., 2011; 2(1): 256-259.

[15] Chaitanya R, Sandhya S, David B, Vinod KR, Murali S. HRBC Membrane Stabilizing Property of Roor, Stem and Leaf of Glochidionvelutinum. Int J Res Pharmacist Biomed Sci., 2011; 2(1): 256-259.Chang, S.-T., Miles, P. G. 2004. Mushrooms: Cultivation, Nutritional Value, Medicinal Effect, and Environmental Impact, $2^{\text {nd }}$ ed.; Boca Raton, FL, USA: CRC Press.

[16] Chippada SC, Volluri SS, Bammidi SR, Vanglapati M. In vitro anti-inflammatory activity of methanolic extract of Centellaasiatica by HRBC membrane stabilization. Rasayan J Chemistry, 2011; 4(2): 457-460.

[17] Chippada SC, Volluri SS, Bammidi SR, Vanglapati M. In vitro anti-inflammatory activity of methanolic extract of Centellaasiatica by HRBC membrane stabilization. Rasayan J Chemistry, 2011; 4(2): 457-460.

[18] Circu ML, Aw TY. Reactive oxygen species cellular redox system and apoptosis. Free Radical Biology and Medicine, 2010; 48: 749-762.

[19] Circu ML, Aw TY. Reactive oxygen species cellular redox system and apoptosis. Free Radical Biology and Medicine, 2010; 48: 749-762.

[20] Feirrali M, Signormi C, Ciccolili L, Comporti M. Iron release and membrane damage in erythrocytes exposed to oxidizing agents, phenyl hydrazine, devicene and iso-uranil. Biochem Journal, 1992; 285: 295-301.

[21] Feirrali M, Signormi C, Ciccolili L, Comporti M. Iron release and membrane damage in erythrocytes exposed to oxidizing agents, phenyl hydrazine, devicene and iso-uranil. Biochem Journal, 1992; 285: 295-301.

[22] Grice HC. Safety evaluation of butylated hydroxyanisole from the prospective of effects on fore stomach and esophageal squamous epithelium. Food and Chemichal Toxicology, 1988; 26: 717-723.

[23] Grice HC. Safety evaluation of butylated hydroxyanisole from the prospective of effects on forestomach and oesophageal squamous epithelium. Food and Chemichal Toxicology, 1988; 26: 717-723.

[24] Gulcin I. The antioxidant and radical scavenging activity of black pepper (Piper nigrum) seeds. International Journal of Food Sciences and nutrition, 2005; 56: 491-499.

[25] Gulcin I. The antioxidant and radical scavenging activity of black pepper (Piper nigrum) seeds. International Journal of Food Sciences and nutrition, 2005; 56: 491-499.
[26] Hamzah RU, Jig am A A, Makun HM, Egwim E C. Phytochemical screening and antioxidant activity of methanolic extract of selected wild edible Nigerian mushrooms. Asian Pacific Journal of Tropical Disease, 2014; 4(1): 153-157.

[27] Hamzah RU, Jigam A A, Makun HM, Egwim E C. Phytochemical screening and antioxidant activity of methanolic extract of selected wild edible Nigerian mushrooms. Asian Pacific Journal of Tropical Disease, 2014; 4(1): 153-157.

[28] Hung PV, Morita N. Distribution of phenolic compounds in the graded flours milled from

[29] Hung PV, Morita N. Distribution of phenolic compounds in the graded flours milled from

[30] Jeong EM, Liu M, Sturdy M, Gao G. Varghese ST, Sovari AA. Metabolic stress, reactive oxygen species and arthythmia. Journal of Molecular and Cellular Cardiology, 2012; 52: 454463.

[31] Jeong EM, Liu M, Sturdy M, Gao G. Varghese ST, Sovari AA. Metabolic stress, reactive oxygen species and arthythmia. Journal of Molecular and Cellular Cardiology, 2012; 52: 454463.

[32] Jia ZS, Tang MC, Wu JM. The determination of flavonoid contents in mulberry and their scavenging effects on superoxide radicals. Food Chemistry, 1999; 64: 555-99.

[33] Jia ZS, Tang MC, Wu JM. The determination of flavonoid contents in mulberry and their scavenging effects on superoxide radicals. Food Chemistry, 1999; 64: 555-99.

[34] Kalac P. Chemical composition and nutritional value of European species of wild growing mushrooms. In S. Andres and N. Baumann (Eds), Mushrooms: Types properties and nutrition Nova Science Publishers, 2012; 130-151

[35] Kalac P. Chemical composition and nutritional value of European species of wild growing mushrooms. In S. Andres and N. Baumann (Eds), Mushrooms: Types properties and nutrition Nova Science Publishers, 2012; 130-151.

[36] Ashagrie Z. Woldegiorgis, Dawit Abate, Gulelat D. Haki, Gregory R. Ziegler. Proximate and Amino Acid Composition of Wild and Cultivated Edible Mushrooms Collected from Ethiopia Journal of Food and Nutrition SciencesVol. 3, No. 2, 2015, pp. 47-54. doi: 10.11648/j.jfns.20150302.14

[37] Masumi Kamiyama, Takayuki Shibamoto, Masahiro Horiuchi, Katsumi Umano, Kazuo Kondo, Yuzuru Otsuka, Antioxidant/Anti-Inflammatory Activities and Chemical Composition of Extracts from the Mushroom Trametes Versicolor, International Journal of Nutrition and Food Sciences. Vol. 2, No. 2, 2013, pp. 85-91. doi: 10.11648/j.ijnfs.20130202.19. 